\title{
High Performance Indoor Air Quality Specification for Net Zero Energy Homes
}

Prepared By: Berkeley Analytical Associates, LLC, http://www.berkeleyanalytical.com

- Bernheim + Dean Inc, http://www.bernheimdean.com

- White + GreenSpec

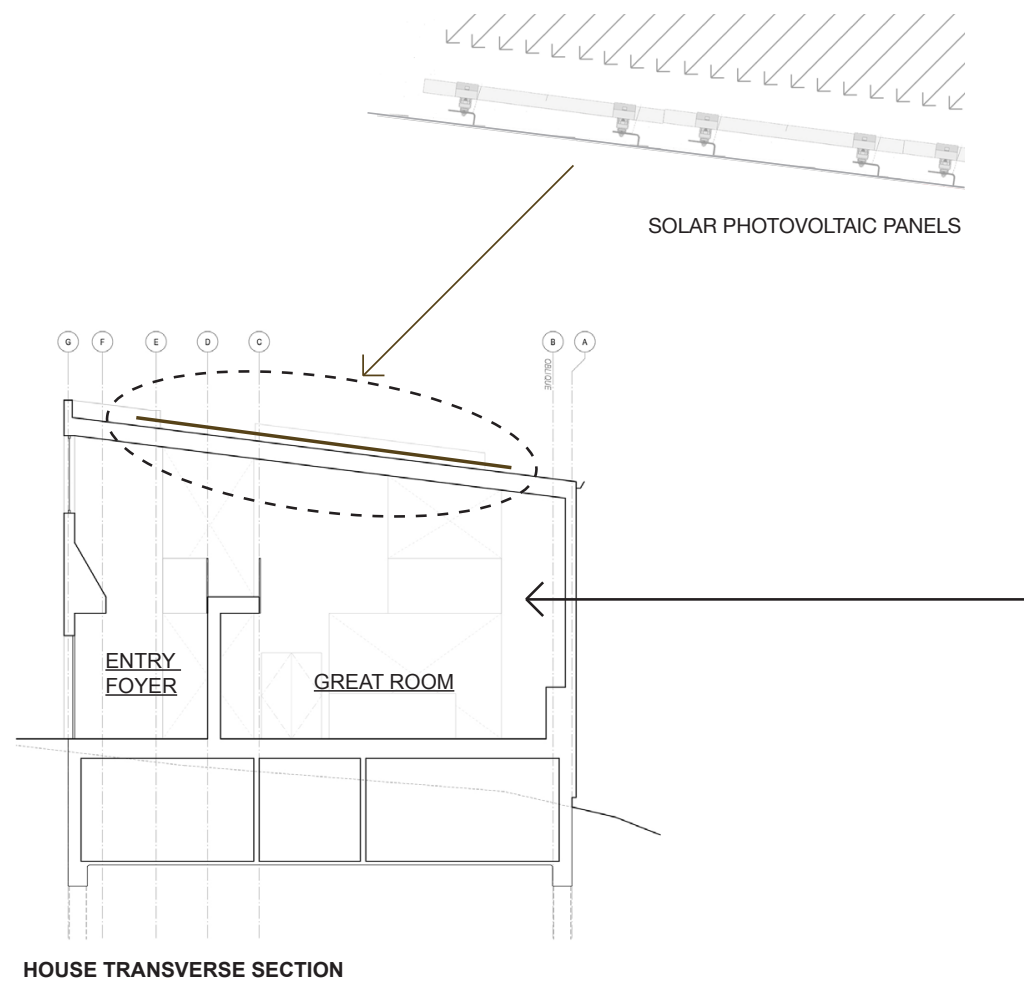

\section{SHEET NOTES:}

1. INTERIOR MATERIALS AND PRODUCTS SHALL MEET THE REQUIREMENTS OF SPECIFICATION SECTION 0181 13.01: SUSTAINABILITY REQUIREMENTS - INDOOR AIR QUALITY.

2. EMISSIONS FOR INTERIOR MATERIALS, PRODUCTS AND FINISHES SHALL MEET THE CALIFORNIA DEPARTMENT OF PUBLIC HEALTH (CDPH) STANDARD METHOD V1.1, 2010 REQUIREMENTS FOR MODELED INDOOR AIR CONCENTRATIONS BASED ON THE PRIVATE OFFICE SCENARIO (SECTION 4.3.5)

3. COMPOSITE WOOD PRODUCTS SHALL HAVE NO ADDED FORMALDEHYDE RESIN BINDER

4. ADHESIVES AND SEALANTS SHALL NOT CONTAIN FORMALDEHYDE OR A FORMALDEHYDE PRECURSOR AS AN INGREDIENT

5. PAINTS SHALL NOT CONTAIN FORMALDEHYDE AS AN INGREDIENT OR CONTAIN CHEMICALS THAT REACT IN THE PRODUCT TO PRODUCE FORMALDEHYDE 
NIST GCR 14-980

\title{
High Performance Indoor Air Quality Specification for Net Zero Energy Homes
}

\author{
Prepared for \\ U.S. Department of Commerce \\ Engineering Laboratory \\ National Institute of Standards and Technology \\ Gaithersburg, MD 20899-8633
}

Berkeley Analytical Associates, LLC

Bernheim + Dean Inc

White + GreenSpec

http://dx.doi.org/10.6028/NIST.GCR.14-980

January, 2015

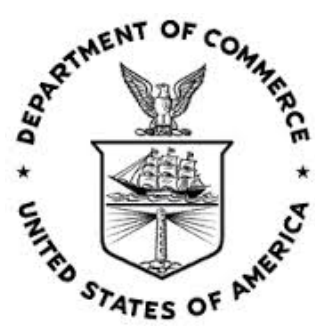

U.S. Department of Commerce Penny Pritzker, Secretary

National Institute of Standards and Technology Willie May, Acting Under Secretary of Commerce for Standards and Technology and Acting Director

berkeley analytical

Bernheim + Dean, Inc.

Sustainable Building Consultants

White + GreenSpec 


\section{BACKGROUND}

The NIST Energy and Environment Division provides scientific leadership to help the U.S. achieve its vision of net zero energy (NZE) buildings. In 2009, the Division received funding to design, construct and operate a Net Zero Energy Residential Test Facility (NZERTF) in Gaithersburg, MD. The NZERTF was conceived as a typical residence for a family of four that can be operated to achieve net zero site energy use on an annual basis. The facility, completed in 2012 , is a $250-\mathrm{m}^{2}\left(2,700-\mathrm{ft}^{2}\right)$, two-story, single-family residence with a substantially improved thermal envelope and a variety of other energy-saving features. It functions as a laboratory to support the development and adoption of cost-effective NZE designs and technologies, construction methods, and building codes. A simulated occupancy test was initiated in mid-2013. The NZERTF achieved its primary goal of generating more energy than it consumed during the year-long study despite an abnormally severe winter (NIST, 2014).

The approach used for the design of the NZERTF is described in detail by Pettit et al. (2014). The first principle was to design for the comfort level and functions needed by the presumed occupants. The other principles related directly to the building structure and systems. The principles included siting to maximize renewable energy potential, establishing an airtight building enclosure, providing controlled ventilation, installing insulation that exceeded building codes, providing for water and moisture control in the building enclosure, and installing highly efficient mechanical equipment, lighting and appliances.

Indoor air quality (IAQ) directly impacts the comfort, health and wellbeing of building occupants, and the achievement of acceptable IAQ in newly constructed and renovated buildings is a well-recognized design objective. For example, IAQ is addressed by major high-performance building rating systems and building codes (California Building Standards Commission, 2014; USGBC, 2014). Indoor air quality in homes is particularly important because Americans, on average, spend approximately ninety percent of their time indoors with the majority of this time spent at home (EPA, 2011). Some segments of the population that are most susceptible to the effects of poor IAQ, such as the very young and the elderly, occupy their homes almost continuously. Additionally, an increasing number of adults are working from home at least some of the time during the workweek.

The concentrations of many air pollutants often are elevated in homes relative to outdoor air because many of the materials and products used indoors contain and release a variety of pollutants to air (Hodgson et al., 2002; Offermann and Hodgson, 2013). With respect to indoor air contaminants for which inhalation is the primary route of exposure, the critical design and construction parameters are the provision of adequate ventilation and the reduction of indoor sources of the contaminants.

In order to support indoor environmental design goals in the NZERTF, both of these pollutant control techniques were considered in its design. The ventilation system design and specifications are described in Pettit et al. (2014). In order to control indoor contaminant sources, guidelines for the selection of products used inside of the airflow control layer (or air barrier 
membrane) were developed under contract to NIST by Berkeley Analytical. The intent of these guidelines was to identify and use products with relatively low emissions of volatile organic compounds (VOCs) that are toxic, cause sensory irritation and/or have low odor thresholds. Particular emphasis was placed on reducing known sources of formaldehyde emissions such as composite woods containing conventional resins. VOCs emitted from wet-applied materials and acetic acid, an odorant and suspected chemical irritant found in numerous interior products, also were targeted.

These guidelines were largely prescriptive based on published research and product information available at the time. The guidelines existed outside of the NZERTF architectural specifications. The design team implemented the guidelines to the best of their ability. Implementation was, in part, an iterative process in which Berkeley Analytical reviewed information on products and product alternatives and provided recommendations for use. The design team noted that, in general, it was difficult for product manufacturers and suppliers to verify that the IAQ requirements were met except for the relatively simple product credits described in the LEED for Homes building standard (Pettit et al., 2014).

Despite the challenges, the IAQ objectives for the NZERTF largely were accomplished. The impacts of the efforts to limit airborne concentrations of formaldehyde and other VOCs in the facility by providing adequate ventilation and implementing source control were investigated through an IAQ monitoring study conducted over the course of the year-long simulated occupancy test (Poppendieck et al., 2014). This study concluded that the measures taken to reduce the use of medium density fiberboard and particleboard in the cabinetry and other finished products were effective for controlling indoor formaldehyde concentrations. The results additionally suggested that specifications for low-emitting interior products used in the construction of NZE homes with ventilation per ASHRAE Standard 62.2(ASHRAE, 2013b) could result in residences with lower indoor VOC emission rates and VOC concentrations than typical new homes that do not include this design parameter.

\section{SPECIFICATION SECTION 018113.01}

Based on the lessons learned in their application to the NZERTF, the guidelines for low-emitting interior sources have been updated and formalized into architectural specification language. Under a NIST contract, Bernheim + Dean, Inc. (with specification assistance by White + GrenSpec) and Berkeley Analytical have developed a detailed architectural Division 01 specification, "Section 0181 13.01, Sustainability Requirements - Indoor Air Quality" intended specifically for residential new construction and major renovations. This specification differs substantially from the original guidelines and emphasizes a more performance-based approach than the guidelines. This change is made possible by the existence today of considerably more product data on VOC emissions that has been generated by manufacturers interested in demonstrating compliance of their products to LEED low-emitting materials credits and the requirements of other high-performance building standards and codes. The specification itself is 
provided at the end of this document and is available for download in Word format at the NZERTF website at www.nist.gov.

The Specification Section 0181 13.01, Sustainability Requirements - Indoor Air Quality, aims to provide guidance for professionals on IAQ topics for the design and construction of a "healthy" NZE home. It is intended to be used by:

1. Architects:

a. The specification provides guidance to architects as they review, select, and specify systems and products for their residential projects.

b. Project specifications are developed in sections within Divisions from 00 and 01 through 48. Division 01 sections apply to all the other sections in the specification. Hence, it provides the IAQ requirements that apply throughout.

2. Contractors and Design-Build Contractors:

a. The specification provides guidance to Contractors and Design-Build Contractors as they review, select, and specify systems and products for residential projects when they are the design and construction lead.

b. The specification also is intended to assist Contractors who are building homes based on an Architect's specifications, in their research on high-performance systems and products.

The specification was developed using the Construction Specifications Institute (CSI) standard format. It contains three parts plus appendices:

1. Part 1 - General. This part provides general requirements for systems and products including: meetings; project submittal documents; product substitutions, quality assurance; delivery, storage and handling; project conditions; and cleaning, protection and other environmental issues.

2. Part 2 - Products:

a. This part describes the attributes and requirements for the typical systems and products used in residential construction.

b. The requirements for these systems and products should not be repeated within the individual systems and product specification sections. The individual systems and product sections should be referenced to Section 0181 13.01, Sustainability Requirements - Indoor Air Quality, using the language in document 0000 00, IAQ Sustainability Template, provided with the Division 01 specification section.

c. The intent of using a Division 01 section is to provide all of the IAQ requirements in one location that can be updated as needed without having to update the entire specification document.

3. Part 3 -Execution. This part provides guidance to the building system and product installer on requirements that need to be implemented during construction. It covers mold and 
moisture control, IAQ management plans, special provisions for attached garages, protection of HVAC equipment, general housekeeping, and scheduling.

4. Appendices:

a. Appendix A provides a variety of references and other resources for specification users who would like more in depth information.

b. Appendix B provides definitions for specification users who may be unfamiliar with the terminology related to IAQ and associated topics.

It is recognized that each residential project will have different objectives and requirements based on the owner's programmatic requirements, site conditions, climatic conditions, project size and complexity, and other factors. Accordingly, the specification is intended and designed to be modified by the user. Editor's notes are provided throughout the Specification section (in blue font) to guide the user in selecting appropriate requirements and in editing the document consistent with the specific project requirements. The user should read the Editor's notes, make their project specific decisions, edit the document to incorporate their decisions, and delete the Editor's notes prior to issuing the document for construction.

An Indoor Air Quality Compliance Table also is provided to assist the specification user in tracking the IAQ compliance requirements for systems and products in the Specification section and for recording submittal documentation. Such documentation includes VOC emission test reports, product technical data sheets, material safety data sheets (MSDS), product certifications and manufacturer's self-declared claims, if applicable.

\section{ADDITIONAL TOPICS}

Control measures for pollutants that are less volatile and that may expose occupants by pathways other than, or in addition to, inhalation are not as well established as control measures for VOCs. Thus, the IAQ specification does not directly address these pollutants in Part 2 on product requirements. Nevertheless, sources of low volatility pollutants may be reduced by restricting the use of products containing these pollutants. To assist the specification user interested in expanding the scope of potential pollutants, the specification includes optional requirements that may be used to limit products based on information about material and product ingredients.

Building commissioning is another topic of potential interest that is not covered in the IAQ specification. Building commissioning is the process of verifying that the building is built and operates as designed and as intended. The expected outcome of the commissioning process is a building that meets the occupants' requirements and operates efficiently with good air quality. Commissioning should start early in the design process and continue throughout the design and construction phases and potentially extend into the occupancy phase.

Specification users who wish to incorporate commissioning should develop a process that is appropriate for the type, size, and complexity of their residential project in accordance with industry guidelines, building code requirements, and USGBC LEED certification requirements 
(if required). It is expected that the commissioning of a multi-story multi-family building will be more complex than the commissioning of a single family home. Currently, two related commissioning processes are described in national guidelines that may be expanded to include IAQ requirements:

i. Building Commissioning $(\mathrm{Cx})$ - commissioning of the mechanical, electrical, plumbing and renewable energy generation systems. Cx should be developed based on ASHRAE Guideline 0-2013, The Commissioning Process (or latest version) (ASHRAE, 2013a).

ii. Building Enclosure Commissioning (BECx) -commissioning of the building enclosure that involves building envelope design and construction review to minimize air filtration, improve sound isolation, and improve energy efficiency. BECx should be developed based on the National Institute of Building Science (NIBS) Guideline 3-2012 (or latest version) (NIBS, 2012).

\section{REFERENCES}

ASHRAE (2013a). Standard 0-2013 - - The Commissioning Process. American Society of Heating, Refrigerating and Air-Conditioning Engineers, Inc., Atlanta, GA. Accessible at http://www.techstreet.com/ashrae?ashrae_auth_token=.

ASHRAE (2013b). Standard 62.2-2013: Ventilation and Acceptable Indoor Air Quality in LowRise Residential Buildings. American Society of Heating, Refrigerating and AirConditioning Engineers, Inc., Atlanta, GA. Accessible at http://www.techstreet.com/ashrae?ashrae_auth_token=.

California Building Standards Commission (2014). 2013 California Green Building Standards Code. California Code of Regulations, Title 24, Part 11. Accessible at http://www.bsc.ca.gov/Home/CALGreen.aspx.

EPA (2011). Exposure Factors Handbook: 2011 Edition, Chapter 16 - Activity Factors. Report EPA/600/R-09/052F, September 2011. U.S. Environmental Protection Agency, Washington, D.C. Accessed at http://www.epa.gov/ncea/efh/report.html September 23, 2014.

Hodgson, A. T., D. Beal, J.E.R. McIlvaine (2002). Sources of formaldehyde, other aldehydes and terpenes in a new manufactured house. Indoor Air 12: 235-242.

NIBS (2012). Guideline 3-2012, Building Enclosure Commissioning Process, BECx. National Institute of Building Sciences, Washington, D.C. Accessible at http://www.nibs.org/?page=reports.

NIST (2014). NIST Test House Exceeds Goal; Ends Year with Energy to Spare. NIST Tech Beat, July 1, 2014. Accessed at http://www.nist.gov/el/building_environment/netzero070114.cfm, September 23, 2014. 
Offermann, F. J. and A. T. Hodgson (2011). Emission Rates of Volatile Organic Compounds in New Homes. Proceedings Indoor Air $2011\left(12^{\text {th }}\right.$ International Conference on Indoor Air Quality and Climate 2011). June 5-10, 2011, Austin, TX USA.

Pettit, B., C. Gates, H. Fanney, W.M. Healy (2014). Design Challenges of the NIST Net Zero Energy Residential Test Facility. NIST Technical Note, September 2014. U.S. Department of Commerce, National Institute of Standards and Technology. Gaithersburg, MD. Accessed at http://www.buildingscience.com/documents/reports/rr-1401-design-challenges-nist-net-zeroenergy-residential-test-facility September 23, 2014.

Poppendieck, D., L. Ng, M. Schlegel, A. Persily, A. Hodgson (2014). Long-term air quality monitoring in a Net-Zero Energy Residential Test Facility designed with specifications for low emitting interior products. Paper HP0087, Proceedings Indoor Air $2014\left(13^{\text {th }}\right.$ International Conference on Indoor Air Quality and Climate, 2103), July 7-12, 2014, Hong Kong.

USGBC (2014). LEED ${ }^{\circledR}$ BD+C Homes v4. U.S. Green Building Council, Washington, D.C. Accessed at http://www.usgbc.org/credits/homes/v4. 
The specifications are provided on the pages that follow. They are also available for download in Word format at the NZERTF website at www.nist.gov. 
This publication is available free of charge from: http://dx.doi.org/10.6028/NIST.GCR.14-980 


\section{SECTION 000000 - SUSTAINABILITY TEMPLATE}

Editor's Note: This template is to be used with guide specification Section 018113.01 "Sustainability Requirements - Indoor Air Quality." The template includes only the paragraphs relevant to indoor air quality, for insertion into the relevant technical Sections of projects with IAQ requirements. Selectively copy and paste contents of this section to meet Project-specific indoor air quality requirements in each technical section, in accordance with CSI Section Format and as applicable to scope of each section.

This Section uses the term "Contractor." Change this term to match that used to identify the design professional as defined in the General and Supplementary Conditions.

PART 1 - GENERAL

\section{$1.1 \quad$ SUMMARY}

Editor's Note: Edit the following according to specification Sections prepared for project.

A. Related Requirements:

1. Sustainability Requirements - General 018113.

2. Sustainability Requirements - Indoor Air Quality, Section 018113.01.

3. Sustainability Requirements - Resource Efficiency, Section 018113.02.

4. Sustainability Requirements - LEED, Section 018116.

\section{PART 2 - PRODUCTS}

\section{$2.1 \quad$ SUSTAINABLE PRODUCTS}

Editor's Note: Copy and paste this ARTICLE into the relevant technical specification Sections. Edit the Section numbers in the paragraphs below according to what is included in the project.

A. General: Products in this section may also be required to comply with sustainability requirements described in Sections 01 8113, 01 8113.01, and 018113.02 and 01 8116; including, but not limited to, the following:
1. Energy efficiency.
2. Water efficiency.
3. VOC content.
4. VOC emissions.
5. Chemical content.
6. Renewable or bio-based material content.
7. Sustainable forestry.
8. Life Cycle Analysis (LCA) or Durability.
9. <Add additional sustainable strategies if they apply.>

Editor's Note: Insert paragraph below into technical specification Sections that specify INTERIOR composite wood and agrifiber products.

B. Composite Wood and Agrifiber Products, Indoor Air Quality: Products shall comply with requirements specified in Section 01 8113.01. 
Editor's Note: Insert paragraph below into technical specification Sections that specify INTERIOR wall and ceiling system products (i.e.: gypsum board, insulation, acoustic ceiling tile, and wall coverings).

C. Wall and Ceiling Systems, Indoor Air Quality: Products shall comply with requirements specified in Section 01 8113.01.

Editor' Note: Insert paragraph below into technical specification Sections that specify INTERIOR floor assembly products (i.e.: wood flooring, resilient base and accessories, resilient flooring, resinous flooring, and carpeting).

D. Flooring Systems, Indoor Air Quality: Products shall comply with requirements specified in Section 018113.01.

Editor's Note: Insert paragraph below into technical specification Sections that specify INTERIOR FIELD-APPLIED paint and coating system products.

E. Field-Applied Interior Paints and Coatings, Indoor Air Quality: Products shall comply with requirements specified in Section 018113.01.

\subsection{ADHESIVES, MASTICS, GLUES, AND SEALANTS}

Editor's Note: Insert paragraph below into technical specification Sections that specify INTERIOR FIELD-APPLIED adhesive, mastics, glues and sealant system products.

A. General: Do not use products that contain urea-formaldehyde.

B. VOC Limits: Products shall comply with requirements specified in Section 018113.01.

PART 3 - EXECUTION - NOT USED

END OF SECTION 000000 


\section{SECTION 0181 13.01 - SUSTAINABILITY REQUIREMENTS - INDOOR AIR QUALITY}

Editor's Note: This Division 01 Section of the architectural specification is intended to be used by design professionals as a specification for building products, systems and processes that contribute to indoor air quality in single family and multifamily low-rise and multifamily mid-rise residential projects. It is provided with comments to the specification writer and must be edited as required to comply with specific Project requirements. The Section is focused primarily on indoor air quality (IAQ) and other related environmental impacts and should be coordinated with other Technical Sections that specify environmental requirements for each of the building systems and products. It may also be used as a guide for the selection of products, rather than including it as a Specification Section.

At the end of this Section are two Appendices: Appendix A - References and Resources, and Appendix $\mathrm{B}$ - Definitions. These appendices are intended as resources for the specification writer and may be selectively added into the text or deleted entirely in the final edit of this Section. Another resource is the IAQ Compliance Table, which is displayed at the end of this document and is available for download in Excel format at the NZERFT website at www.nist.gov. This table provides a simple checklist and tracking tool for IAQ specifications.

In addition, there is a Sustainability Template that provides instructions to the specification writer on how to coordinate and edit the specification technical Sections with this Division 01 IAQ section. Suggested paragraphs are proposed for insertion into the Technical Specification Sections.

Delete Editor's Notes after the editing of this Specification Section is complete.

PART 1 - GENERAL

Editor's Note: Retain the following Article if this Section is included within a full Project Manual and this Article is included in all Sections, otherwise delete it.

\section{$1.1 \quad$ RELATED DOCUMENTS}

A. Drawings and general provisions of the Contract, including General and Supplementary Conditions and other Division 01 Specification Sections, apply to this Section.

\section{$1.2 \quad$ SUMMARY}

A. Section includes administrative and procedural requirements governing specifications for achieving indoor air quality (IAQ) objectives for the project.

1. General: Interior construction assemblies, systems, materials, products and finishes, including but not limited to: insulation, partitions, partition coverings, flooring, floor coverings, wall coverings, ceiling finishes, adhesives, sealants, glazing, paints, casework and similar materials shall be manufactured, handled, and installed in such a manner to reduce health and comfort (including odor) effects on building occupants.

2. The requirements of this Section relate to both site-applied and shop fabricated materials and products.

\subsection{MEETING REQUIREMENTS}

A. General: Include Owner, Contractor, Architect and relevant subcontractors in IAQ meetings.

SUSTAINABILITY REQUIREMENTS - INDOOR AIR QUALITY $\quad 018113.01$ - 
B. Preconstruction Conference: Include IAQ in the agenda of the Preconstruction Conference at Project site prior to start of construction. Review IAQ requirements for interior assemblies, materials, products and finishes.

C. Project Meetings: Include an update on the status of IAQ requirements at each regularly scheduled meeting as needed.

\section{$1.4 \quad$ SUBMITTALS}

A. General: Coordinate IAQ submittals with other submittal requirements specified in the Technical Specification Sections, including material descriptions, product characteristics, and finishes; include IAQ data on furnished specialties and accessories.

B. IAQ Product Data, General: For each type of material and product listed below that is used interior to the exterior waterproofing membrane, provide the following IAQ Product Data:

1. VOC Content of Paints and Coatings: Product data indicating Volatile Organic Compound (VOC) content in grams per Liter $(\mathrm{g} / \mathrm{L})$. Options:

a. Manufacturer's Technical Data Sheet, or

b. Copy of product label.

2. VOC Content for Adhesives and Sealants: Product data indicating Volatile Organic Compound (VOC) content in grams per Liter $(\mathrm{g} / \mathrm{L})$. Options:

a. Manufacturer's Technical Data Sheet, or

b. Copy of product label.

3. Formaldehyde Content:

a. Composite Wood and Agrifiber Products: Product data indicating No Added Formaldehyde (NAF) resin system for composite wood and agrifiber products from options listed below.

b. Insulation: Data for each batt, blanket and wet-spray insulation product indicating binder is not formaldehyde based. Data for spray-in-place insulation showing product is not formed by reacting an amine chemical group with formaldehyde.

4. Product Data for Carpet Systems:

a. For carpet and carpet cushion, documentation indicating compliance with testing requirements of CRI's (Carpet and Rug Institute) "Green Label Plus" program. If alternative testing by CDPH (California Department of Public Health) Standard Method V1.1 is used, provide documentation as specified in Section C below.

b. For installation adhesive, documentation of VOC content in $\mathrm{g} / \mathrm{L}$.

c. NSF/ANSI 140 Sustainability Assessment for Carpet: Documentation indicating certified conformance level for broadloom and carpet tile products.

5. Product Data for Resilient and Tile Flooring and Flooring Adhesives: Documentation indicating compliance with testing requirements of Resilient Floor Covering Institute (RFCI) FloorScore ${ }^{\mathrm{TM}}$ program. If alternative testing by CDPH Standard Method V1.1 is used, provide documentation as specified in Section $\mathrm{C}$ below.

6. Cleaning Products: Provide data for cleaning products used during regular construction cleaning and for final cleaning indicating compliance with standards and programs promoting use of safer ingredients such as U.S. EPA Design for the Environment (DfE) and Green Seal standards GS-37, GS-40 and GS-53. 
C. IAQ Emission Test Data and Certifications: The following documentation and certifications are acceptable for each interior product and finish that are required in the Technical Specification Sections to be tested for VOC emissions in accordance with CDPH Standard Method V1.1:

1. IAQ Test Data, General: Test report produced by an ISO/IEC 17025 accredited laboratory showing emission factors of emitted VOCs. Test shall have been conducted within three (3) years of the start date of Notice to Proceed for or commencement of construction of the project.

2. Manufacturer's Self Declarations: Manufacturer's declaration of compliance with CDPH Standard Method V1.1 based on laboratory testing as described above.

3. Third Party Certifications: In lieu of declaration of compliance by the manufacturer, certification of compliance with CDPH Standard Method V1.1 made by a third party, ISO/IEC 17065 accredited certification body.

Editor's Note: Edit following paragraph according to project location and specified product types.

D. Wood and Agrifiber Product Certifications: For each nonstructural composite wood and agrifiber product required to be IAQ compliant in the Technical Sections, the following documentation is acceptable:

1. California: Certification or copy of product label indicating that wood and agrifiber product is classified as No Added Formaldehyde (NAF) and is compliant with the California Air Resources Board (CARB) Airborne Toxic Control Measure (ATCM) for Composite Wood (17 CCR 93120 et seq.).

2. Outside of California, Manufacturer's Self Declarations: Manufacturer's declaration or product data sheet indicating that product is produced using NAF resin binder

Editor's Note: If product transparency is a Project requirement, identify the products (or numbers of products or dollar value of products) requiring documentation and select from the following options, otherwise delete.

E. Building Product Transparency for Material Ingredients: The following documentation and certifications are acceptable:

1. Health Product Declaration (HPD): Manufacturer's publically available Heath Product Declaration (HPD) with full disclosure of ingredients and known hazards that is in compliance with the Health Product Declaration Standard 1.0, 2012, and is verified by an ISO/IEC 17065 accredited certification body.

2. Chemical Inventory: Manufacturer's publically available chemical inventory of product ingredients to at least 0.1 percent $(1,000 \mathrm{ppm})$ with all ingredients identified by name and Chemical Abstract Registration Number (CASRN). Name and CASRN of substance defined as trade secret or intellectual property may be withheld, but inventory shall disclose role, amount, and hazard benchmark rating of substance, as defined in GreenScreen v1.2.

3. Environmental Product Declaration (EPD): Manufacturer's product life cycle assessment documenting environmental impact of the product throughout its life cycle (i.e., from cradle to cradle) that is verified by an ISO/IEC 17065 accredited certification body.

F. Moisture-Protection Plan: Contractor's plan describing procedures and controls for protecting materials and construction from water absorption and damage.

1. Describe delivery, handling, and storage provisions for materials subject to water absorption or water damage. 
2. Describe procedures for discarding water-damaged materials, protocols for mitigating water intrusion into completed Work, and replacing water-damaged Work.

3. Describe sequencing of work that requires water, such as sprayed fire-resistive materials, plastering, and concrete grinding. Describe plans for managing water from these operations. Show procedures for verifying that wet construction has dried sufficiently to permit installation of finish materials.

\subsection{SUBSTITUTIONS}

A. Substitution requests for product types specified or indicated in the Contract Documents are also governed by this Section and shall meet the minimum requirements specified herein. Substitution requests shall require documentation indicating compliance with the relevant requirements specified in this Section.

1. For products where compliance with specified IAQ requirements may not be possible, alternative IAQ solutions shall be developed by the Contractor and approved by Architect before being implemented.

\subsection{QUALITY ASSURANCE}

A. Coordination: Coordinate IAQ management activities with additional environmental requirements specified in Division 01 through Division 49 Specification Sections

B. Laboratory Test Requirements: Laboratory tests shall be performed by ISO/IEC 17025 accredited laboratories.

C. Third Party Certification and Verification Requirements: Certification and verification of environmental product claims shall be performed by ISO/IEC 17065 accredited certification bodies.

\subsection{DELIVERY, STORAGE, AND HANDLING}

A. Products used on the project shall be as new, shall not have been exposed to water, and shall not have visible mold or mildew growth.

B. Moisture Protection: Protect interior materials from water intrusion or penetration.

1. Porous or fibrous materials with visible mold or mildew growth shall not be installed and shall be removed from the site and disposed of appropriately.

2. Notify Owner and Architect immediately that mold or mildew is detected. Once discovered, no onsite or offsite treatment of mold and mildew with cleaning agents or other chemicals, including ozone, is permitted.

3. Keep porous and organic materials from coming into prolonged contact with any concrete surface.

4. Remove standing water from decks; keep deck openings covered to prevent water intrusion into the project.

\section{$1.8 \quad$ PROJECT CONDITIONS}

A. Provide and maintain controlled interior environmental conditions in accordance with mechanical engineer's requirements before beginning installation of interior finish materials. 
B. Smoking shall not be permitted in indoor and outdoor Project site locations. 
C. Construction Ventilation and Preconditioning, General:

1. Comply with ventilation and testing requirements specified in Mechanical Technical Specification Sections, or as directed by Mechanical Engineer.

2. Provide temporary ventilation for one hour prior to, during, and for 24 hours after completion of installation of interior products that emit vapors from organic solvents.

1.9 CLEANING AND PROTECTION, ENVIRONMENTAL ISSUES

A. Cleaning Agents, General: Use cleaning products and agents recommended by or acceptable to manufacturer or fabricator of the surface to be cleaned. Do not use cleaning agents that are potentially hazardous to health or property or that may damage finished surfaces. Preferentially use cleaning agents with safer ingredients as defined by governmental or non-governmental programs.

Editor's Note: Edit following paragraphs according to project design and modify where appropriate.

B. Final Cleaning, Environmental Issues: Use nontoxic cleaning and maintenance products as described in this Section.

1. Comply with IAQ Management Plan During Construction, Housekeeping, as specified in this Section.

2. Clean interior and exterior surfaces exposed to view; remove temporary labels, stains, and foreign substances; polish transparent and glossy surfaces.

3. Clean equipment and fixtures to sanitary condition.

4. Remove and properly dispose of recyclable materials using a specified construction waste management program.

\section{PART 2 - PRODUCTS}

\section{$2.1 \quad$ PERFORMANCE REQUIREMENTS}

A. General: These requirements apply to interior building materials, products, and finishes located within the weatherproofing system, unless otherwise noted.

B. Volatile Organic Compound (VOC) Emissions: Emissions for interior materials, products and finishes shall meet the California Department of Public Health (CDPH) Standard Method v1.1, 2010 requirements for modeled indoor air concentrations based on the private office scenario (Section 4.3.5).

C. Volatile Organic Compound (VOC) Content, Adhesives and Sealants: Site applied adhesives and sealants shall comply with South Coast Air Quality Management District (SCAQMD) Rule 1168, Adhesive and Sealant Applications, amended January 52005.

D. Volatile Organic Compound (VOC) Content, Paints and Coatings: Site applied paints and coatings shall comply with one or both of the following:

1. South Coast Air Quality Management District (SCAQMD) Rule 1113, Architectural Coatings, amended September 6, 2013.

2. California Air Resources Board (CARB) Suggested Control Measure (SCM) for Architectural Coatings, 2007. 
E. Composite Wood and Agrifiber Products for interior non-structural use:

1. California: Composite wood products shall comply as No Added Formaldehyde (NAF) under California Air Resources Board (CARB) Airborne Toxic Control Measure (ATCM) for Composite Wood (17 CCR 93120 et seq.). Note that product labels showing compliance are required for most composite wood and agrifiber products sold and used within the State of California but are optional in other jurisdictions. Labels should indicate products are NAF compliant.

2. California (but not included under CARB ATCM): Products shall be produced using NAF resin binder.

3. Outside of California: Products shall be produced using NAF resin binder.

Editor's Note: Retain one or both of the paragraphs below if the project is required to meet the US Green Building Council (USGBC) LEED ${ }^{\circledR}$ for Homes v4 or LEED for Homes Mid-Rise Multi-Family v4; and/or International Living Futures Institute (ILFI) Living Building Challenge (LBC) v3.0. Note that the detailed requirements for these rating systems will be specified elsewhere in the Project Manual.

F. US Green Building Council LEED v4 Requirements: If the project is required to comply with the USGBC LEED® for Homes v4 or LEED for Homes, Mid-Rise Multi-Family v4 Green Building Rating systems, comply with requirements of appropriate prerequisites and credits as indicated and specified for use on this Project.

G. International Living Futures Institute (ILFI) Living Building Challenge (LBC) v3.0

Requirements: Comply with requirements of Petals and Imperatives performance categories as indicated and specified for use on this Project.

\subsection{PRODUCTS, GENERAL}

A. General: These requirements are in addition to the performance requirements indicated above.

Editor's Note: For projects outside California, the SCAQMD Rule 1168 still applies, although the product labeling may not indicate "meets Rule 1168." Conformance to Rule 1168 may be demonstrated by testing using EPA Method 24, other applicable test method, or by calculation from formulation. Edit the following according to the types of adhesives that will be used in the Project interior. VOC content requirements may need to be updated to be consistent with most current version of rule.

B. Adhesives and Sealants:

1. No adhesive and sealant shall contain formaldehyde or a formaldehyde precursor as an ingredient.

2. Silicone rubber caulks and sealants containing acetic acid as an ingredient only are permitted to be used in limited quantity in kitchen, bath and utility areas where it is necessary to obtain a water-tight seal.

3. SCAQMD Rule 1168: For field applications that are inside the weatherproofing system, adhesives and sealants shall comply with the following VOC content limits when calculated as required in Rule 1168 as amended January 2005, or most current version:

a. Wood Glues: $30 \mathrm{~g} / \mathrm{L}$.

b. Metal-to-Metal Adhesives: $30 \mathrm{~g} / \mathrm{L}$.

c. Adhesives for Porous Materials (Except Wood): $50 \mathrm{~g} / \mathrm{L}$.

d. Subfloor Adhesives: $50 \mathrm{~g} / \mathrm{L}$.

e. Plastic Foam Adhesives: $50 \mathrm{~g} / \mathrm{L}$. 
f. Carpet Adhesives: $50 \mathrm{~g} / \mathrm{L}$.

g. Carpet Pad Adhesives: $50 \mathrm{~g} / \mathrm{L}$.

h. VCT and Asphalt Tile Adhesives: $50 \mathrm{~g} / \mathrm{L}$.

i. $\quad$ Cove Base Adhesives: $50 \mathrm{~g} / \mathrm{L}$.

j. Gypsum Board and Panel Adhesives: $50 \mathrm{~g} / \mathrm{L}$.

k. Rubber Floor Adhesives: $60 \mathrm{~g} / \mathrm{L}$.

1. Ceramic Tile Adhesives: $65 \mathrm{~g} / \mathrm{L}$.

m. Multipurpose Construction Adhesives: $70 \mathrm{~g} / \mathrm{L}$.

n. Fiberglass Adhesives: $80 \mathrm{~g} / \mathrm{L}$.

o. Contact Adhesive: $80 \mathrm{~g} / \mathrm{L}$.

p. Structural Glazing Adhesives: $100 \mathrm{~g} / \mathrm{L}$.

q. Wood Flooring Adhesive: $100 \mathrm{~g} / \mathrm{L}$.

r. Structural Wood Member Adhesive: $140 \mathrm{~g} / \mathrm{L}$.

s. $\quad$ Special-Purpose Contact Adhesive: $250 \mathrm{~g} / \mathrm{L}$.

t. Top and Trim Adhesive: $250 \mathrm{~g} / \mathrm{L}$.

u. Adhesive Primer for Plastic: $550 \mathrm{~g} / \mathrm{L}$.

v. Aerosol Adhesive, General-Purpose Mist Spray: 65 percent by weight.

w. Aerosol Adhesive, General-Purpose Web Spray: 55 percent by weight.

x. $\quad$ Special-Purpose Aerosol Adhesive (All Types): 70 percent by weight.

y. $\quad$ Other Adhesives: $250 \mathrm{~g} / \mathrm{L}$.

z. Architectural Sealants: $250 \mathrm{~g} / \mathrm{L}$.

aa. Other Sealants: $420 \mathrm{~g} / \mathrm{L}$.

bb. Sealant Primers for Nonporous Substrates: $250 \mathrm{~g} / \mathrm{L}$.

cc. Sealant Primers for Porous Substrates: $775 \mathrm{~g} / \mathrm{L}$.

dd. Other Sealant Primers: $750 \mathrm{~g} / \mathrm{L}$.

Editor's Note: For projects outside California, the SCAQMD Rule 1113 still applies, although the product labeling may not indicate "meets Rule 1113." Alternately, projects outside of California may use the CARB SCM VOC limits. Conformance to Rule 1168 and SCM may be demonstrated by testing using EPA Method 24, ASTM D6886, other applicable test method, or by calculation from formulation. Edit the following according to which set of criteria the Project will follow and the types of paints and coatings that will be used in the Project interior. VOC content requirements may need to be updated to be consistent with most current version of rule or regulation.

C. Paints and Coatings:

1. No paint and coating shall contain formaldehyde as an ingredient or contain chemicals that react in the product to produce formaldehyde.

2. All finish coatings shall be formulated with water-based technologies (i.e., water-based polyurethane, acrylic/polyurethane, acrylic, UV, or polyester) with the exceptions that solvent-based wipe stains may be used as wood finishes and epoxy coatings may be used in small areas for specialty applications.

3. Paints and coatings applied to interior doors, casework and other components produced offsite shall comply with the requirements given below.

4. SCAQMD Rule 1113: For field applications that are inside the weatherproofing system, paints and coatings shall comply with the following VOC content limits when calculated as required in Rule 1113 as amended September 2013:

a. Flat Paints and Coatings: $50 \mathrm{~g} / \mathrm{L}$.

b. Non-flat Paints and Coatings: $150 \mathrm{~g} / \mathrm{L}$.

c. $\quad$ Primers, Sealers, and Undercoaters: $200 \mathrm{~g} / \mathrm{L}$. 
d. Anticorrosive and Antirust Paints Applied to Ferrous Metals: $250 \mathrm{~g} / \mathrm{L}$.

e. Zinc-Rich Industrial Maintenance Primers: 340 g/L.

f. $\quad$ Pretreatment Wash Primers: $420 \mathrm{~g} / \mathrm{L}$.

g. $\quad$ Clear Wood Finishes, Varnishes: $350 \mathrm{~g} / \mathrm{L}$.

h. $\quad$ Clear Wood Finishes, Lacquers: $550 \mathrm{~g} / \mathrm{L}$.

i. Floor Coatings: $100 \mathrm{~g} / \mathrm{L}$.

j. $\quad$ Shellacs, Clear: $730 \mathrm{~g} / \mathrm{L}$.

k. Shellacs, Pigmented: $550 \mathrm{~g} / \mathrm{L}$.

1. Stains: $250 \mathrm{~g} / \mathrm{L}$.

5. CARB SCM, Table 1: For field applications that are inside the weatherproofing system, paints and coatings shall comply with the following VOC content limits when calculated as required by the SCM:

a. Flat Coatings: $50 \mathrm{~g} / \mathrm{L}$.

b. Non-flat Coatings: $100 \mathrm{~g} / \mathrm{L}$.

c. Non-flat - High Gloss Coatings: $150 \mathrm{~g} / \mathrm{L}$.

d. Wood Coatings: $275 \mathrm{~g} / \mathrm{L}$.

e. Floor Coatings: $100 \mathrm{~g} / \mathrm{L}$.

f. Primers, Sealers and Undercoaters: $100 \mathrm{~g} / \mathrm{L}$.

g. Stains: $250 \mathrm{~g} / \mathrm{L}$.

h. Concrete/Masonry Sealers: $100 \mathrm{~g} / \mathrm{L}$.

D. Thermal and Acoustic Insulation, General:

1. Insulation material, including mineral/rock wool insulation, shall not contain formaldehyde-based binder as an ingredient.

2. Insulation material shall be fire retardant free unless required by local building code.

E. Carpet and Carpet Cushion:

1. Comply with Carpet and Rug Institute (CRI) "Green Label Plus" program testing requirements for carpet and the "Green Label" program testing requirements for carpet cushion.

2. ANSI/NSF 140: For carpet, meet Achievement Level of Gold, 52 to 70 points, based on specific Sustainable Attribute Performance for all product stages according to ANSI/NSF 140.

F. Resilient and Tile Flooring: Comply with Resilient Floor Covering Institute (RFCI)

"FloorScore ${ }^{\circledR, " ~ p r o g r a m ~ t e s t i n g ~ r e q u i r e m e n t s ~ f o r ~ f l o o r i n g ~ a n d ~ f l o o r i n g ~ a d h e s i v e s . ~}$

Editor's Note: Thermoset decorative resin finishes on panel products are discouraged.

G. Wood, Composite Wood, Agrifiber Products and Components: Manufactured, prefinished, and engineered wood products shall comply with indicated VOC requirements:

1. Moldings and Trim: Interior moldings and trim materials shall be solid wood or fingerjointed wood. No MDF or other composite wood products shall be used for moldings and trim.

2. Shelving and Panels: Built-in shelving, including closet shelving and organizers, and wood panels applied to walls, columns and other structures, shall consist of hardwood plywood (HWPW) with no-added formaldehyde (NAF) veneer core. 
3. Stair Components: Stair components (handrails, balusters, posts, treads, risers and stringers) shall be solid wood. Alternately treads and risers may consist of hardwood plywood (HWPW) with NAF veneer core.

4. Built-In Casework, General:

a. Casework cases shall employ either solid wood or all plywood construction (APC) including end panels, ceilings, floors, backs, shelves and interior support beams.

b. Casework drawers shall consist of solid wood drawer sides and HWPW NAF drawer bottoms.

c. Casework interiors shall be finished wood veneer, high-pressure laminate or equivalent.

d. Finish coatings shall be water-based polyurethane, acrylic/polyurethane, acrylic, $\mathrm{UV}$, or polyester. Finish coatings shall not contain or produce formaldehyde (i.e., acid cured or catalyzed finishes are prohibited).

5. Interior Doors, General: Preferred Option, interior doors shall be solid wood construction.

H. Countertops, General:

1. Kitchen, bath and utility countertops shall be concrete, stone, recycled paper composite, recycled plastic, terrazzo or other products that meet the specified VOC requirements of this Section.

2. Countertops shall be installed over substrates that are in compliance with the VOC requirements of this Section.

I. Gypsum Board Walls and Ceilings, General:

1. Attachment Method: Paper-faced and paperless gypsum wall board (GWB) shall be applied with conventional mechanical fasteners. Solvent-containing adhesives shall not be used for application of gypsum board.

2. Gypsum board shall comply with VOC emissions testing as indicated in this Section.

Editor's Note: Retain the following paragraph if restriction of Living Building Challenge Red List Materials is a project requirement; otherwise delete. Utilize the International Living Future Institute "Declare" label to demonstrate product compliance. Detailed LBC requirements should be specified in a separate Division 01 Sustainable Design Requirements Section.

J. Living Building Challenge (LBC) Red List Materials: Subject to specific exceptions as defined by the Living Building Challenge v3.0, products shall not contain Red List Materials as listed in the Materials Petal, Responsible Industry Imperative 10.

Editor's Note: The following requirements for product transparency are optional, and information may not be available for all products, so aiming for a small percentage of the products on the project may be appropriate until more product transparency information becomes available. Incorporate only if the project Owner requires this information. Select the appropriate certification(s) based on the project requirements.

K. Environmentally Preferable Products, Transparency: Provide at least 20 products on the project having documentation of one or more of the following:

1. Health Product Declaration Collaborative: Completed Health Product Declaration (HPD) Standard, latest version. 
2. Cradle to Cradle Products Innovation Institute: Cradle to Cradle Certified V3.0; Silver Level minimum.

3. International Living Future Institute: Living Building Challenge; Declare label.

4. Environmental Product Declarations (EPD): Manufacturer's Environmental Product Declaration. 


\section{PART 3 - EXECUTION}

\subsection{MOISTURE AND MOLD CONTROL}

Editor's Note: This is a general guide only; develop specific procedures for each project.

A. General: Protect materials as follows:

1. Do not load or install drywall, other porous materials and components, and items with high organic content into partially enclosed building.

2. Keep interior spaces clean and protected from water damage; periodically collect and remove waste containing cellulose or other organic matter.

3. Comply with manufacturer's written instructions for storage of products with respect to temperature, relative humidity, and water exposure limits.

4. Document visible signs of mold and mildew that may appear during construction. Report findings in writing to Owner and Architect.

\subsection{CONSTRUCTION IAQ MANAGEMENT DURING CONSTRUCTION}

Editor's Note: The procedures indicated below are intended to ensure that the project site will remain clean during the construction process and to avoid the contamination of materials as they are installed. Construction IAQ management requirements specified below are based upon practices described in Sheet Metal and Air Conditioning Contractors National Association (SMACNA) IAQ Guidelines for Occupied Buildings under Construction (latest version). Retain requirements that apply based on the size and type of project. Modify references to HVAC requirements according to type and size of Project systems. Retain HVAC requirements for Mid-Rise Multi-Family projects with building HVAC systems installed. Retain Pathway Interruption, Housekeeping, and Scheduling and edit paragraphs to facilitate appropriate level of IAQ management for Project.

A. Construction IAQ Management Plan During Construction: General IAQ Plan requirements during construction include:

1. Attached Garage Pollutant Protection.

2. HVAC protection.

3. Source control.

4. Pathway interruption.

5. Housekeeping.

6. Scheduling.

Editor's Note: Retain below if Project includes a garage attached to the living quarters of single family home.

B. Attached Garage Pollutant Protection, General:

1. Enclose garage with air barrier to completely separate the habitable area of the home from the garage. The air barrier material shall be installed from the floor slab to the structure above. Gypsum board assemblies shall be sealed at the top and bottom with sealants that comply with the IAQ requirements of this Section.

2. Install weather stripping or gasket and threshold on all passageways between living space and attached garage.

3. Provide an exhaust fan with automatic timer controls linked to an occupant sensor, light switch, garage door opening mechanism, a carbon monoxide sensor that turns on the fan 
when the garage $\mathrm{CO}$ level reaches $35 \mathrm{ppm}$, or equivalent. Fan shall be vented directly outdoors, have a minimum capacity of $75 \mathrm{cfm}$ and be capable of ventilating garage space at three air changes per hour for a typical two car garage. Fan shall operate for at least one hour after event triggering fan operation.

C. HVAC Protection:

1. Use of permanent heating, cooling, and ventilating systems during construction period is not permitted.

2. Comply with SCMACNA requirements for protection of air handling and distribution equipment and air supply and return ducting during construction.

3. Adequately cover and protect exposed air inlets and outlets, openings, grilles, ducts, plenums, as required to prevent water, moisture, and other contaminant intrusion.

4. Apply protection immediately after installation of equipment and ducting.

5. Ducting runs that require more than a single day to install shall be protected at the end of each day's work.

6. Replace air filtration media immediately prior to occupancy.

D. Pathway Interruption:

1. All openings within the designated work area shall be sealed while wet work is being performed to prevent contamination in adjacent areas.

2. Temporary ventilation shall be exhausted to the outside of the building.

E. Housekeeping:

1. Provide temporary ventilation during construction to minimize accumulation of dust fumes, vapors, or gases in the building.

2. Continuously ventilate during and after installation of materials that emit VOCs until emissions dissipate:

a. Period after installation shall be sufficient to dissipate odors and elevated levels of VOCs. Provide temporary ventilation for one hour prior to, during, and for 24 hours after completion of installation of VOC emitting products.

b. Ventilate areas directly to outside, do not ventilate to other enclosed spaces.

c. Ventilate via open windows and temporary fans that provide no less than three air changes per hour.

3. Use dust collection attachments on saws, sanders, and other power tools that generate dust particles.

4. Suppress dust with wetting agents or sweeping compounds.

5. Clean-up dust using a wet rag or damp mop.

6. Increase the cleaning frequency when dust build-up is noted.

7. Remove spills or excess applications of solvent-containing products as soon as possible.

8. Remove accumulated water and keep work areas as dry as possible.

9. Store and keep volatile liquid containers closed when the container is inside of the building and not in use.

10. HEPA vacuuming and duct cleaning.

a. Vacuum carpeted and soft surfaces with a high efficiency particulate arrestor (HEPA) vacuum.

b. If ducts contain dust and dirt, clean them using a HEPA vacuum immediately before substantial completion and prior to using the ducts to circulate air.

c. Oil film on sheet metal should be removed before shipment to site. Ducts shall be inspected to confirm that no oil film is present. Remove oil that may be remaining. 
11. Use nontoxic cleaning materials and procedures. 
F. Scheduling:

1. General: Comply with manufacturer's instructions for appropriate drying times.

2. Protect installed absorbent materials with recycled or recyclable materials.

3. Where odorous and/or high VOC-emitting products are applied on site, apply them before installation of porous and fibrous materials. Where this is not possible, protect porous materials with polyethylene vapor retarders.

4. Insure that wet applied interior finish materials, such as paints, adhesives, sealants, coatings, finishes, and spray-applied materials, such as structural fireproofing, are properly and fully cured before installing other finish materials over them.

5. Install carpets and furnishings after all other interior finish materials have been applied and fully cured.

6. Provide adequate ventilation of packaged dry products prior to installation. If space is available, remove from packaging and ventilate in a secure, dry, well-ventilated space free from strong contaminant sources and residues.

7. Complete interior finish material installation no less than 14 days prior to Substantial Completion to allow for building flush-out.

\subsection{CONSTRUCTION IAQ MANAGEMENT PLAN BEFORE OCCUPANCY}

Editor's Note: The procedures indicated below are intended to remove contaminants that may be present due to the construction process. Edit following paragraph according to project design, or delete Article if it is not required by Owner. Note that the following is scaled down for multi family low-rise residential application.

A. Construction IAQ Testing Plan Before Occupancy: Comply with the following requirements:

1. After construction ends, prior to occupancy and with all interior finishes installed, perform a building flush-out.

2. Flush for at least 48 hours total; the hours may be non-consecutive if necessary.

3. Keep operable windows and interior doors open and run HVAC system fan (or large portable commercial fan) continuously, or flush home with HVAC system fans and exhaust fans (or large portable commercial fans) operating continuously at the highest flow rate.

4. Use additional temporary large portable commercial fans to circulate air within the house.

5. Replace air filtration media immediately prior to occupancy.

6. If required by Owner; perform IAQ testing following LEED v4 for Interior Design and Construction, Option 2 air testing procedures, or alternate procedure developed by qualified IAQ Engineer.

END OF SECTION 
Editor's Note: Both Appendix A and B are intended to be resources for the specification writer's further research and understanding of IAQ standards and definitions. These Appendices should be deleted once the Section editing is completed.

\section{APPENDIX A - REFERENCES AND RESOURCES}

\subsection{REFERENCES AND RESOURCES}

A. Airborne Toxic Control Measure (ATCM) 93120-93120.12, Title 17, California Code of Regulations.

B. American Society of Heating, Refrigerating and Air Conditioning Engineers (ASHRAE)

1. ASHRAE Standard 52.2: Method of Testing General Ventilation Air-Cleaning Devices for Removal Efficiency by Particle Size (ANSI Approved) for defining Minimum Efficiency Reporting Value (MERV).

a. $\quad$ Minimum efficiency Reporting Value (MERV) of 8 for filtration media.

b. $\quad$ Minimum efficiency Reporting Value (MERV) of 13 for filtration media.

2. ASHRAE Standard 62.1: Ventilation for Acceptable Indoor Air Quality (ANSI Approved).

a. Sections 4 through 7.

b. Definition of minimum outdoor air rate.

3. ASHRAE Standard 62.2: Ventilation and Acceptable Indoor Air Quality in Low-Rise Residential Buildings.

C. ASTM International (ASTM)

1. ASTM D1356: Standard Terminology Relating to Sampling and Analysis of Atmospheres.

2. ASTM D5116: Guide for Small Scale Environmental Chamber determination of Organic Emissions from Indoor Materials/Products.

3. ASTM D5197: Standard Test Method for Determination of Formaldehyde and Other Carbonyl Compounds in Air (Active Sampler Methodology).

4. ASTM D6329: Standard Guide for Developing Methodology for Evaluating the Ability of Indoor Materials to Support Microbial Growth Using Static Environmental Chambers.

5. ASTM D6345: Standard Guide for Selection of Methods for Active, Integrative Sampling of Volatile Organic Compounds in Air.

6. ASTM D6670: Standard Practice for Full-Scale Chamber Determination of Volatile Organic Emissions from Indoor Materials/Products.

7. ASTM D6886: Standard Test Method for Determination of the Individual Volatile Organic Compounds (VOCs) in Air-Dry Coatings by Gas Chromatography

8. ASTM D7339: Standard Test Method for Determination of Volatile Organic Compounds Emitted from Carpet using a Specific Sorbent Tube and Thermal Desorption / Gas Chromatography.

9. ASTM E2114: Standard Terminology for Sustainability Relative to the Performance of Buildings.

D. Cal/EPA, California Air Resources Board (CARB)

1. Airborne Toxic Control Measure (ATCM) for formaldehyde in composite wood products: http://www.arb.ca.gov/toxics/compwood/compwood.htm 
2. Architectural and Industrial Coatings Program (AIM) - 2007 Suggested Control Measure (SCM), 2008: http://www.arb.ca.gov/coatings/arch/docs.htm

3. Toxic Air Contaminants (TACs). Current version of list is accessible at http://www.arb.ca.gov/toxics/id/taclist.htm

E. Cal/EPA, Office of Environmental Health Hazard Assessment (OEHHA)

1. Non-cancer health effects. Acute, 8-hour and Chronic Reference Exposure Levels (RELs). Current version of this list is accessible at http://oehha.ca.gov/air/allrels.html

2. Safe Drinking Water and Toxic Enforcement Act or 1986 (Proposition 65). Current version of list is accessible at http://www.oehha.ca.gov/prop65/prop65 list/newlist.html

F. CALGreen: 2013 California Green Building Standards Code, California Code of Regulations, Title 24, Part 11. Current version of code is accessible at https://law.resource.org/pub/us/code/bsc.ca.gov/

G. California Department of Public Health (CDPH), CDPH/EHLB/Standard Method V1.1: Standard Method for the Testing and Evaluation of Volatile Organic Chemical Emissions from Indoor Sources Using Environmental Chambers, Version 1.1 (Emission Testing Method for California Specification 01350); accessible at http://www.cal-iaq.org/separator/voc/standardmethod

H. Carpet and Rug Institute (CRI): Green Label Plus Certification for carpet and carpet cushion; accessible at http://www.carpet-rug.org/

I. Cradle to Cradle Products Innovation Institute: Cradle to Cradle (C2C) Certified Products Program; accessible at http://www.c2ccertified.org/product_certification/c2ccertified_product_standard

J. Green Seal; accessible at http://www.greenseal.org/FindGreenSealProductsAndServices.aspx

1. Green Seal Standard GS-11, Paints and Coatings.

2. Green Seal Standard GS-36, Adhesives for Commercial Use.

3. Green Seal Standard GS-42, Commercial and Institutional Cleaning Services.

4. Green Seal Standard GS-49, Residential Cleaning Services.

K. GreenScreen for Safer Chemicals: Method for chemical hazard assessment; accessible at http://www.greenscreenchemicals.org/

L. Health Product Declaration Collaborative; Health Product Declaration (HPD) Standard Version 1.0; accessible at http://hpdcollaborative.org

M. International Green Construction Code (IgCC); accessible at http://www.iccsafe.org/CS/IGCC/Pages/default.aspx

N. International Living Futures Institute (ILFI); accessible at http://living-future.org/lbc.

1. Living Building Challenge (LBC) Standard 3.0, 2014.

2. Material Petals Handbook, 2013

3. Declare, The Ingredients Label for Building Products; accessible at www.declareproducts.com. 
O. International Organization for Standardization (ISO)

1. ISO 14021:2001. Environmental labels and declarations. Self-declared environmental claims (Type II environmental labeling).

2. ISO 16000-9:2006. Indoor Air - Part 9: Determination of the Emission of Volatile Organic Compounds from Building Products and Furnishing - Emission Test Chamber Method.

3. ISO/IEC 17025:2005 General Requirements for the Competence of Testing and Calibration Laboratories.

4. ISO/IEC 17065: 2012 Conformity Assessment - Requirements for Bodies Certifying Products, Processes and Services

5. ISO/IEC Guide 65:1996 General Requirements for Bodies Operating Product Certification Systems.

P. $\quad$ North East Ozone Transport Commission (OTC)

1. $\quad$ Model Rule 2009-12; Architectural \& Industrial Maintenance (AIM) Coatings.

2. Model Rule for Adhesives and Sealants.

Q. Resilient Floor Covering Institute (RFCI): FloorScore emissions criteria and testing method for hard surface flooring and flooring adhesives; accessible at SCS Global Services website http://www.scsglobalservices.com/floorscore

R. Sheet Metal and Air Conditioning Contractors National Association (SMACNA): IAQ Guidelines for Occupied Buildings Under Construction, 2nd Edition 2007, ANSI/ SMACNA 008-2008 (Chapter 3).

S. South Coast Air Quality Management District (SCAQMD)

1. SCAQMD Rule 1113, Architectural Coatings: VOC limits for AIM paints and coatings; accessible at: http://www.aqmd.gov/rules/reg/reg11/r1113.pdf

2. SCAQMD Rule 1168, Adhesive and Sealant Applications: VOC limits for primers, adhesives, sealants, and sealant and other primers; accessible at: http://www.arb.ca.gov/drdb/sc/curhtml/r1168.pdf

T. US Environmental Protection Agency (EPA)

1. Indoor airPLUS Construction Specifications, Version 1 (Rev. 02): http://www.epa.gov/indoorairplus

2. 40 CFR 59, Subpart D, Method 24, Determination of Volatile Matter Content, Water Content, Density, Volume Solids, and Weight Solids of Surface Coatings; accessible at http://www.epa.gov/ttnemc01/promgate/m-24.pdf

3. Building Radon Out (EPA 402-K-01-002): Building Radon Out: A Step-by-Step Guide On How to Build Radon-Resistant Homes, 2001; accessible at http://www.epa.gov/radon/pdfs/buildradonout.pdf

4. Environmentally Preferable Purchasing Guidelines for Cleaning Agents; accessible at http://www.epa.gov/opptintr/epp/pubs/cleaning.htm

5. Map of Radon Zones; accessible at http://www.epa.gov/radon/zonemap.html

6. Toxic Substances Control Act (TSCA), Section 5(b)(4): Chemicals of Concern; accessible at http://www.epa.gov/oppt/existingchemicals/index.html

U. US Green Building Council (USGBC) 
1. Leadership in Energy and Environmental Design (LEED), LEED for Homes Design and Construction, v4. Includes 'Homes and Multifamily Lowrise' and 'Multifamily'; accessible at http://www.usgbc.org/leed/v4

2. USGBC Buyer's Guide to Green Countertops; accessible at:

http://greenhomeguide.com/know-how/article/buyers-guide-to-green-countertopmaterials 


\section{APPENDIX B - DEFINITIONS}

\subsection{DEFINITIONS}

A. Absorption: The process of one substance entering into the inner structure of another. (U.S. $E P A)$.

B. Absorptive Materials: Materials capable of absorption.

C. Adsorption: The adhesion of a thin film of liquid or gases to the surface of a solid substance. (U.S. EPA).

D. Air Change Rate: Ratio of volume of conditioned air brought into the emission test chamber or building space per unit time to the chamber or building space volume. (CDPH IAQ Standard Method V1.1, 2010).

E. Allergen: A chemical or biological substance (e.g., pollen, animal dander, or house dust mite proteins) that induces an allergic state or reaction, characterized by hypersensitivity. A substance that induces allergic reaction. (USEPA, 2012).

F. Annoyance: A general feeling of displeasure or adverse psychological reaction toward a source. Associated with disturbance, distress and frustration. (USEPA, 2012).

G. ASHRAE: American Society of Heating, Refrigerating, and Air-Conditioning Engineers is an international group which is organized for the purpose of advancing the arts and sciences of heating, ventilation, air conditioning and refrigeration through research, standards writing, continuing education and publications. See www.ashrae.org. (US EPA, 2012).

H. Asthma: A condition marked by recurrent attacks of difficult or labored breathing and wheezing resulting from spasmodic contraction and hypersecretion of the bronchi. It is caused by exposure to allergens such as drugs, foods, environmental pollutants, or intrinsic factors. (US EPA, 2012).

I. ASTM International: American Society for Testing and Materials, a consensus-based standard setting organization. See www.astm.org. (US EPA, 2012).

J. Breathing Zone: Area of a room in which occupants breathe as they stand, sit, or lie down. (US EPA, 2012).

K. Building Flush Out: A process used to remove VOCs from a building by operating the building's HVAC system at 100 percent, tempered outside air for a specific period of time.

L. Building-Related Illness (BRI): Diagnosable illness whose symptoms can be identified and whose cause can be directly attributed to airborne building pollutants (e.g., Legionnaire's disease, hypersensitivity pneumonitis). Also: A discrete, identifiable disease or illness that can be traced to a specific pollutant or source within a building. (Contrast with "Sick building syndrome"). (US EPA, 2012).

M. Carcinogen: A substance that can cause or contribute to cancer. (US EPA, 2012). 
N. CDPH/EHLB/Standard Method V1.1: Standard Method for the Testing and Evaluation of Volatile Organic Chemical Emissions from Indoor Sources Using Environmental Chambers Version 1.1. Emission testing method for California Specification 01350. Supersedes previous version "Standard Practice for the Testing of Volatile Organic Emissions from Various Sources Using Small-Scale Environmental Chambers". Prepared by Indoor Air Quality Section, Environmental Health laboratory Branch, Division of Environmental and Occupational Disease Control, California Department of Public Health. February, 2010.

O. Concentration: Mass of VOC per unit air volume expressed at standardized conditions for temperature and pressure (i.e., $298^{\circ} \mathrm{K}, 101.3 \mathrm{kPa}$ ) (CDPH IAQ Standard Method V1.1, 2010).

P. Contaminant: Any physical, chemical, biological, or radioactive substance that can adversely affect air, water or soil. (USEPA, 2012).

Q. CREL - Noncancer chronic reference exposure level developed by Cal/EPA OEHHA. These are inhalation concentrations to which the general population, including sensitive individuals, may be exposed for long periods (10 years or more) without the likelihood of serious adverse systemic effects other than cancer. (CDPH IAQ Standard Method V1.1, 2010).

R. Emission: Pollution discharge from a source. (US EPA, 2012).

S. Emission Factor: Mass of VOC emitted from a specific unit area of product surface per unit time. Other unit measures such as product mass or length may be used as appropriate. (CDPH IAQ Standard Method V1.1, 2010).

T. Emission Rate: Mass of VOC emitted by an entire product or test specimen per unit time. (CDPH IAQ Standard Method V1.1, 2010).

U. Emission Test Chamber: Non-contaminating enclosure of defined volume with controlled environmental conditions for inlet air flow rate, temperature and humidity used for determination of VOC emissions from product test specimens. (CDPH IAQ Standard Method V1.1, 2010).

V. EPA: United States Environmental Protection Agency.

W. HEPA: High efficiency particulate arrestance (filters). (US EPA, 2012).

X. Hypersensitivity: The immune system's exaggerated response to an allergen. (US EPA, 2012).

Y. Hypersensitivity Diseases: Diseases characterized by allergic responses to animal antigens. The hypersensitivity diseases most clearly associated with indoor air quality are asthma, rhinitis, and hypersensitivity pneumonitis. Hypersensitivity pneumonitis is a rare but serious disease that involves progressive lung damage as long as there is exposure to the causative agent. (US EPA, 2012).

Z. IAQ Management Plan: A set of flexible and specific steps for preventing and resolving IAQ problems. (USEPA, 2012).

AA. Indoor Air Quality (IAQ): As defined in ANSIASHRAE Standard 62.2, acceptable indoor air quality is "air towards which a substantial majority of occupants express no dissatisfaction with 
respect to odor and sensory irritation and in which there are not likely to be contaminates at concentrations that are known to pose a health risk."

BB. Indoor Air Pollutant: Particles and dust, fibers, mists, bioaerosols, and gases or vapors. (US $E P A, 2012)$.

CC. Loading Factor: Ratio of the nominal exposed surface area of the product or the test specimen to the volume of the building space or the emission test chamber. (CDPH IAQ Standard Method V1.1, 2010).

DD. Mutagen: Any substance that can cause a change in genetic material. (US EPA, 2012).

EE. Mutagenic: Able to cause a permanent change in the structure of DNA. (US EPA, 2012).

FF. Off-Gassing: The production of gases from the chemical deterioration of a substance over time, and the release of gases from materials into the air. (USEPA, 2012).

GG. Organic Compounds: Chemicals that contain carbon. Volatile organic compounds vaporize at room temperature and pressure. They are found in many indoor sources, including many common household products and building materials. (US EPA, 2012).

HH. Particulate Matter: A state of matter in which solid or liquid substances exist in the form of aggregated molecules or particles. Airborne particulate matter is typically in the size range of 0.01 to 100 micrometers. (US EPA, 2012).

II. Preconditioning: A process of airing out building materials and furnishings to allow the VOCs to emit prior to installation in a building. The preconditioning of unwrapped materials and furnishings should be accomplished in a well ventilated space.

JJ. Pressed Wood Products: A group of materials used in building and furniture construction that are made from wood veneers, particles, or fibers bonded together with an adhesive under heat and pressure. (US EPA, 2012).

KK. Product Category: General group of similar products intended for a particular application and performance, such as vinyl composition tile (VCT), laminated wood flooring, broadloom carpet, sheet vinyl flooring, plywood, oriented strand board (OSB), interior paint, etc. (CDPH IAQ Standard Method V1.1, 2010).

LL. Product Subcategory: Group of products within a product category having similar chemistry, construction, weight, formulation and manufacturing process and which may have a similar VOC emissions profile. (CDPH IAQ Standard Method V1.1, 2010).

MM. Respirable Particles: Respirable particles are those that penetrate into and are deposited in the nonciliated portion of the lung. Particles greater than 10 micrometers aerodynamic diameter are not respirable. (US EPA, 2012).

NN. Sick Building Syndrome (SBS): Term that refers to a set of symptoms that affect some number of building occupants during the time they spend in the building and diminish or go away during periods when they leave the building. SBS cannot be traced to specific pollutants or sources within the building. (Contrast with "Building related illness"). (US EPA, 2012). 
OO. Total Volatile Organic Compounds (TVOCs): Sum of the concentrations of all identified and unidentified VOCs between and including n-pentane through n-heptadecane (i.e., C5 - C17) as measured by the GC/MS TIC method and expressed as a toluene equivalent value. (CDPH IAQ Standard Method V1.1, 2010).

PP. Toxic: Of, affected by, or caused by a toxin; to cause a poisonous reaction. (US EPA, 2012).

QQ. Volatile: 1. Able to evaporate readily. 2. Able to go to gas phase from a liquid or solid phase. (US EPA, 2012).

RR. Volatile Organic Compounds (VOCs): Compounds that vaporize (become a gas) at room temperature. Common sources which may emit VOCs into indoor air include housekeeping and maintenance products, and building and furnishing materials. In sufficient quantities, VOCs can cause eye, nose, and throat irritations, headaches, dizziness, visual disorders, memory impairment; some are known to cause cancer in animals; some are suspected of causing, or are known to cause, cancer in humans. At present, not much is known about what health effects occur at the levels of VOCs typically found in public and commercial buildings. (US EPA, 2012).

SS. VOC Content: Volatile organic compound contained in the product.

TT. VOC Emissions: Volatile organic compounds emitted by a product into the air. 
